\section{Esophageal Strictures \\ Complicating Cytomegalovirus Ulcers in Patients with AIDS}

Cytomegalovirus (CMV) infection frequently complicates the course of acquired immunodeficiency syndrome (AIDS). In the esophagus, CMV produces ulcers, which cause dysphagia and odynophagia. Despite the extensive nature of these ulcerations, complications such as bleeding, tracheoesophageal fistula, or strictures are uncommon $[1,2]$.

We had two HIV-positive patients with CMV esophagitis who, after treatment with ganciclovir, developed dysphagia due to a stricture related to a healed ulcer (Figures 1,2). The stricture formation was not a complication of ganciclovir therapy, but rather a consequence of the ulcer healing $[3,4]$. Subsequent dysphagia was controlled in both cases by esophageal dilatation, using Savary dilators.

Wilcox [5] reported the largest series to date, including $160 \mathrm{HIV}$-infected patients with esophageal ulcers, the majority of which were due to CMV infection. Only 13 of the patients $(8 \%)$ developed strictures, demonstrated by endoscopic follow-up. In 21 CMV-related esophageal ulcers in HIV patients studied at our hospital (unpublished data), only two patients (10\%), developed symptoms (dysphagia) related to strictures after treatment with ganciclovir.

Although it is uncommon, CMV must be added to the list of causes of esophageal strictures. Treatment of the stenosis with Savary dilators appears to be safe, producing marked symptomatic improvement.

\section{Olmos ${ }^{1}$, A. Sanchez Basso ${ }^{1}$}

M. Battaglia ${ }^{1}$, H. Concetti ${ }^{2}$, F. Magnanini ${ }^{2}$

${ }^{1}$ Division of Gastroenterology, Fernández

Hospital, Buenos Aires, Argentina

${ }^{2}$ Division of Pathology, Fernández

Hospital, Buenos Aires, Argentina



Figure 2 Endoscopic appearance of the stricture shown in Figure $\mathbf{1}$

\section{References}

${ }^{1}$ Connolly G, Hawkins D, Harcourt-Webster J, et al. Oesophageal symptoms: their causes, treatment, and prognosis in patients with the acquired immunodeficiency syndrome. Gut 1989; 30: 1033 1039

${ }^{2}$ Wilcox M, Diehl D, Cello J, Margaretten W, Jacobson M. Cytomegalovirus esophagitis in patients with AIDS. Ann Intern Med 1990; 113: 589-593

${ }^{3}$ Goodgame R, Ross P, Kim H, Hook A, Sutton F. Esophageal stricture after cytomegalovirus ulcer treated with ganciclovir. J Clin Gastroenterol 1991; 13: $678-$ 681

${ }^{4}$ Churchill D, Kenton-Smith J, Malin A. Oesophageal stricture complicating cytomegalovirus ulceration in a patient with AIDS. J Infect 1992; 25: 108-109

${ }^{5}$ Wilcox M. Esophageal strictures complicating ulcerative esophagitis in patients with AIDS. Am J Gastroenterol 1999; 94: $339-343$

\section{Corresponding Author}

M. Olmos, M.D.

Dorrego 1940

Edificio $\mathrm{B}-3^{\mathrm{a} C} \mathrm{C}$

1414 Buenos Aires

Argentina

Fax: $\quad+54-11-47751984$

E-mail: molmos@intramed.net.ar 